\title{
The significance of aortic overriding and pulmonary stenosis in tetralogy of Fallot
}

Received: 24 November 2014; Accepted: 28 November 2014; First published online: 9 February 2015

Congratulations to Dr Anderson and his colleagues for their work in the pathway of clarifying the disagreements in the definition and diagnosis of tetralogy of Fallot. ${ }^{1}$ The phenotypic feature of tetralogy of Fallot is malalignment of the outlet septum in combination with abnormal septo-parietal trabeculations such that there is subpulmonary muscular obstruction. ${ }^{1}$ When obstruction within the right ventricular outflow tract is minimal, it can be hard to distinguish tetralogy from the variant of ventricular septal defect with aortic overriding, known as the Eisenmenger defect. $^{2}$ In addition, partially restrictive or nonrestrictive ventricular septal defects can be associated with moderate or severe infundibular pulmonary stenosis protecting the pulmonary vascular bed against increased blood flow, high pulmonary pressure, and the development of pulmonary vascular disease. ${ }^{3}$ In order to make the accurate diagnosis in tetralogy of Fallot and differentiate between tetralogy of Fallot and ventricular septal defect with pulmonary infundibular stenosis, echocardiography may not be adequate. Dynamic MRI and CT investigations would be more beneficial in order to reveal the anatomical details of the malformed heart. This issue is crucial because the definitive treatment of tetralogy of Fallot is surgery including the closure of the ventricular septal defect and transannular patch plasty, whereas pulmonary infundibular stenosis developing secondary to ventricular septal defect could regress after closure of the ventricular septal defect either by surgery or percutaneously. Percutaneous closure could be performed if there is no aortic overriding. If there is some degree of aortic overriding - doubly committed biventricular connection - the closure device may settle on aortic leaflets due to lack of the superior rim. In that case, the closure device may not be applied. If there are infundibular stenosis secondary to ventricular septal defect and overriding aorta, surgical ventricular septal defect closure may be performed earlier so that an additional pulmonary transannular patch plasty is avoided. If there is infundibular stenosis secondary to ventricular septal defect without overriding aorta subaortic ventricular septal defect - early percutanous closure may be performed in order to prevent further progression of infundibular stenosis. In summary, detailed investigation of ventricular septal defect plus pulmonary stenosis should be carried out. Confirming the diagnosis as tetralogy of Fallot requires doublechecking the patient's images and even adding the tomographic or magnetic resonance evaluation. This "sceptical" approach would prevent unnecessary pulmonary transannular patch plasty that itself may stick a life-long disorder to be followed-up. ${ }^{4}$

\section{Ismail Yurekli, Mert Kestelli, Habib Cakir, Sabin Iscan Katip Celebi Universitesi Ataturk Education and Training Hospital, Yeşilyurt, Izmir, Turkey}

\section{References}

1. Anderson RH, Spicer DE, Henry GW, Rigsby C, Hlavacek AM, Mohun TJ. What is aortic overriding? Cardiol Young 2014: 1-14 [Epub ahead of print].

2. Apitz C, Anderson RH, Redington A. Chapter 39: Tetralogy of Fallot with pulmonary stenosis. In: Anderson RH, Baker EJ, Penny DJ, Redington AN, Rigby ML, Wernovsky G (eds). Paediatric Cardiology, 3rd edn. Elsevier Publishing, 1600 John F. Kennedy Boulevard Suite 1800, PA, 19103-2899, Philadelphia, USA, 2009: 39; 4508-4635.

3. Oechslin E. Chapter 21: Cyanosis. In: Siegenthaler W (eds). Differential Diagnosis in Internal Medicine. Georg Thieme Verlag, Rudigerstrasse 14, 70469 Stuttgart, Germany, 2007; 21: 676-711.

4. Yurekli I, Kestelli M, Cakir H. The optimal z-score for transannular patch. Eur J Cardiothorac Surg 2013; 44: 774. Epub April 18, 2013. 